\title{
Effects of three lighting intensities during display on discolouration of beef semitendinosus muscle
}

\author{
Marek Cierach $\cdot$ Jacek Niedźwiedź
}

Received: 4 July 2013 / Revised: 4 April 2014 / Accepted: 5 April 2014 / Published online: 5 May 2014

(C) The Author(s) 2014. This article is published with open access at Springerlink.com

\begin{abstract}
This study focuses on the changes in colour parameters of beef (semitendinosus muscle) upon the light exposure. In one of the experiments (Experiment I), colour parameters were studied during $60 \mathrm{~min}$ of blooming. In the Experiment II, the changes of colour over $168 \mathrm{~h}$ of exposure were evaluated. For this purpose, the white fluorescent light of three different intensities, 500, 1,000 and $1,500 \mathrm{~lx}$, was chosen. It is shown that it takes up to $16-$ $18 \mathrm{~min}$ for the colour parameters to stabilize after the steak cutting, which is a consequence of increasing availability of oxygen. Beef colour is affected by the light intensity. It was observed that at the beginning of the light exposure, favourable changes took place. However, after few days of exposure to the light, meat colour deteriorates significantly. Changes are mainly related to the redness $\left(a^{*}\right)$. The value of $a^{*}$ decreased about 4-7 units $(p<0.05)$ after 7 days of meat exposure. This significant change of redness is also clearly evident in the visual assessment. White fluorescent light (colour temperature of 3,000 K) with intensity of $500 \mathrm{~lx}$ has lower impact on the beef colour than the light with intensity of 1,000 or $1,500 \mathrm{~lx}$. Intensity of $500 \mathrm{~lx}$ is more favourable to preserve the desired beef colour, and it could be recommended to use in the retail display. However, further studies taking into account the visual evaluation of beef colour would be useful to confirm this fact.
\end{abstract}

Keywords Beef - Light intensity · Colour stability · Retail display

M. Cierach · J. Niedźwiedź $(\square)$

Department of Meat Technology and Chemistry, Faculty of Food

Sciences, University of Warmia and Mazury in Olsztyn, Olsztyn, Poland

e-mail: jacek.niedzwiedz@uwm.edu.pl

\section{Introduction}

Since decades, the stability of meat colour is in the interest of research and meat industry, because it is the first criterion of meat evaluation by the purchasers. Meat colour and its variation are for the consumer the main indicator of freshness and wholesomeness of beef [1]. Unfavourable changes in beef colour demonstrate poor quality of meat, lack of freshness, potential microbiological hazards, weak links in the production-distribution chain and even denied safety of beef [2]. If fresh beef is distinguished by redbrown colour, it probably is not desired by consumers and is regarded as unattractive or even spoiled [3].

Meat colour depends on the concentration and chemical form of myoglobin-haem pigment in muscle tissue. The concentration of myoglobin in bovine muscle tissue depends on the breed, age, ante-mortem activity of muscle, sex, method of rearing and animal diet [4]. In a raw, uncured meat, the myoglobin occurs in three different forms: deoxymyoglobin (DMb), oxymyoglobin $(\mathrm{OMb})$ and metmyoglobin (MMb). The partial pressure of oxygen as well as the type and the form of the ligand, which is bonded to the haem iron, determine form of the pigment. Low oxygen pressure favours the presence of $\mathrm{DMb}$ (dark red colour), high oxygen pressure causes oxygenation of myoglobin to $\mathrm{OMb}$, and is responsible for creation of bright red colour of meat. Those two forms of myoglobin (DMb and $\mathrm{OMb}$ ) can be oxidized to $\mathrm{MMb}$, which is responsible for brownish grey colour and is not acceptable for the culinary meat [5]. The amount of myoglobin forms is highly variable during post-mortem changes and meat distribution. To the certain degree, it is possible to reduce MMb by reducing system of muscles, which consists of $\mathrm{MMb}$ reductase depending on NADH and cytochrome b5. This process can take place in aerobic or in anaerobic conditions. 
Unfortunately, both the enzyme activity and the amount of NADH decrease continuously with post-mortem time. Bekhit et al. [6] found that the content of NADH is more important for the stabilization of beef colour than the $\mathrm{MMb}$ reducing activity. The rate of formation of $\mathrm{MMb}$ pigment depends on the type of muscle and is affected by the exposure to the light, $\mathrm{pH}$ value, temperature, microbial contamination, oxidation of lipids, and oxygen partial pressure [7]. In general, low $\mathrm{pH}$ leads to destabilization of haem-binding and increment of oxidation of myoglobin [8]. The light exposure influences the intensification of $\mathrm{MMb}$ formation on meat surface and affects the colour deterioration during storage [9, 10]. Kropf et al. [11] found that the cool white light caused the darkest lean colour and that lean appeared progressively brighter coloured with increasing light intensity. Barbut [12] demonstrated importance of the source and the quantity of light on colour of different meat cuts, when using a specialized fluorescent light bulb in meat display coolers.

Though meat colour and changes in meat colour during exposure to the light are studied since over 30 years, currently, most of the investigations in this field are focused on the changes of beef colour during its light exposure, but in combination with various packaging methods or different kinds of meat treatments designed for improvement in its quality (e.g. injection of salts or organic acids solutions). There is a lack of research focused on assessing the effect of light exposure on beef colour, which would be eliminating all possible differentiating factors. Therefore, the aim of this study was to examine solely the effects of exposure to white fluorescent light $(500,1,000$ and 1,500 lx) on colour stability of raw beef. Moreover, in this study, colour parameters during $60 \mathrm{~min}$ of blooming were examined. On this basis, the time required to meat colour blooming was defined. Results of Experiment I were used to create the assumptions of the experiment II.

\section{Materials and methods}

Animals and treatments

Experiments were carried out on semitendinosus muscle from 24 Limousin x Polish Black-and-White steers (50:50) with a mass in the range from 600 to $700 \mathrm{~kg}$. This muscle was chosen because of its homogeneous structure, even colour over the entire length, and a very low content of intramuscular fat and low marbling. Steers were fed ad libitum grass silage and concentrate (post-extraction rapeseed meal, soybean meal, triticale meal and mineral-vitamin mix). Animals reached a predetermined weight at the age of about 21 months. Transportation of all cattle to slaughterhouse was carried out in the same conditions and took
1-2 $\mathrm{h}$. The slaughter was carried out in accordance to the current EU regulations [13]. Cattle were slaughtered in two batches of 12 animals in two-week interval. Carcasses were not electrically stimulated. Cooling of the carcasses was performed by a two-stage method. For the first hour, the temperature of $-5 \pm 1{ }^{\circ} \mathrm{C}$ was used, and later, for up to 48-h post-mortem, the temperature of $2 \pm 1{ }^{\circ} \mathrm{C}$ was used. The meat temperature at $48 \mathrm{~h}$ was $2 \pm 0.5^{\circ} \mathrm{C}$. After this time, the $\mathrm{pH}$ value was measured in semitendinosus muscle from the right half-carcass. The basis for muscle assignment to the study was $\mathrm{pH}<5.8$. Muscles meeting this criterion were transported to the laboratory and subjected to appropriate treatment. From each muscle, 8 steaks with a thickness of about $2.5 \mathrm{~cm}$ were excised. Steaks were cut perpendicular to the direction of muscle fibres. Two steaks from each muscle were randomly subjected to Experiment I and the other six to Experiment II, two for each treatment. All steaks were assigned to treatment at second-day post-mortem.

$\mathrm{pH}$ value and temperature measurement

Measurements of $\mathrm{pH}$ value and temperature were performed using a pH metre HI 99161 (HANNA instruments US Inc.) with an electrode FC232D (HANNA instruments US Inc.). Prior to measurements, the $\mathrm{pH}$ metre was calibrated to $\mathrm{pH} 4.01$ (HI 5004L, HANNA instruments US Inc.) and 7.01 (HI 5007L, HANNA instruments US Inc.). To read the $\mathrm{pH}$ value, electrode was placed directly in the central part of muscle (to a depth of about $2.5 \mathrm{~cm}$ ) [14]. Three measurements were performed on each muscle.

\section{Experiment I}

In the first experiment, colour parameters during blooming were studied. Measurements were taken at the following time intervals: $0,0.5,1,2,3,5,7,9,14,16,18,20,22$, 26, 30, 40, 50, $60 \mathrm{~min}$ after cutting. Meat was exposed to the white fluorescent light (MASTER TL-D Xtra Secura $36 \mathrm{~W} / 830$ 1SL; colour rendering index $=85 \mathrm{Ra} 8$; colour temperature $=3,000 \mathrm{~K}$; Koninklijke Philips Electronics N.V.). Light intensity of $500 \mathrm{~lx}$ was regulated by adjusting the distance between meat surface and light source. Storage temperature of the meat and temperature of the meat surface when it was oxygenating was $4 \pm 1{ }^{\circ} \mathrm{C}$. During oxygenation, steaks were unwrapped.

\section{Experiment II}

In the second experiment, meat was exposed to the white fluorescent light (MASTER TL-D Xtra Secura 36 W/830 $1 \mathrm{SL}$; colour rendering index $=85 \mathrm{Ra} 8$; colour temperature $=3,000 \mathrm{~K}$; Koninklijke Philips Electronics N.V.). 
Light intensity of 500, 1,000 and 1,500 $\mathrm{lx}$ was regulated by adjusting the distance between meat surface and light source. Exposure was conducted in a refrigerated room at $4 \pm 1{ }^{\circ} \mathrm{C}$. Colour parameters were measured at $30 \mathrm{~min}$ after steaks cutting (after colour blooming which was a result of oxygen access), next at $6 \mathrm{~h}$, and then every 24 up to $168 \mathrm{~h}$ of exposure. All steaks were unpacked during the entire time of experiment, and thus, the relative humidity over the steaks was in the range of 98-100\% (environmental chamber KB 8400 F, TERMAKS). High humidity prevents the meat from excessive drying. The temperature of the meat during measurements was approximately $4{ }^{\circ} \mathrm{C}$. The aim of this study was to test the unwrapped steaks because more often steaks are sold over the counter free of packaging on the butcher stands.

\section{Light intensity measurement}

Light intensity on the surface of steaks was measured using digital luxmeter LM-120 (Amprobe Test Tools, BEHAAMPROBE GmbH).

\section{Colour parameters measurements}

In order to obtain measurements of the same points on the steak surface for the different time intervals, mesh templates for positioning of the device head were used (Fig. 1). Templates were left on the meat during display period. Colour parameters were measured in colour-opponent space CIE $L^{*} a^{*} b^{*}$, by Konica-Minolta colourimeter CR-400 (Konica Minolta Holdings, Inc.), calibrated against white calibration plate CR-A43. $L^{*}$ - colour "lightness", $a^{*}-$ colour "redness", $b^{*}$-colour "yellowness" were determined, and on these basis, $C^{*}$-Chroma and $\Delta \mathrm{E}^{*}$-factor

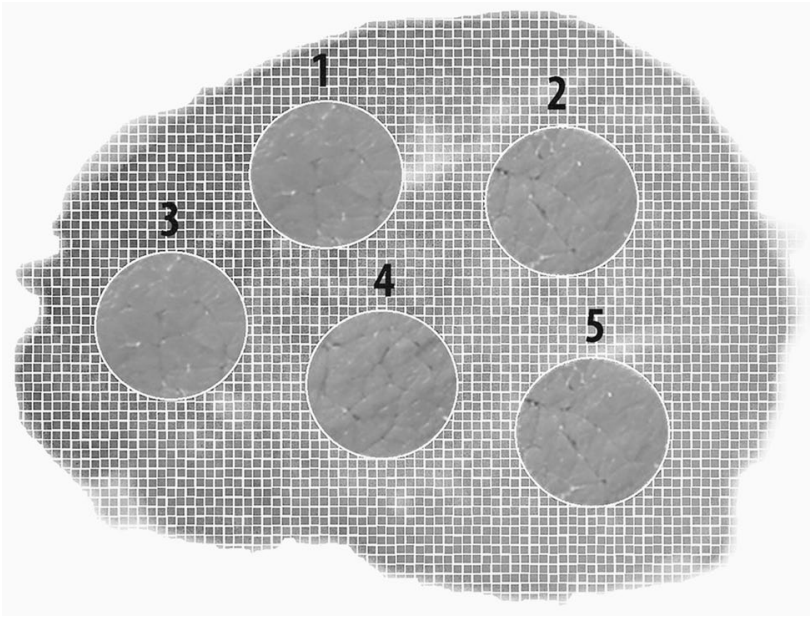

Fig. 1 Measuring points within a cross section of semitendinosus muscle for the experiments of colour differences were calculated. Conditions of measurement were $2^{\circ}$ standard observer, illumination area $8 \mathrm{~mm}$, illuminant D65, diffuse illumination $/ 0^{\circ}$ viewing angle $[15,16]$. In both experiments, at each time interval, one measurement was performed from each of 5 points on the surface of each steak.

$C^{*}=\left(a^{* 2}+b^{* 2}\right)^{0.5}$

$\Delta E^{*}=\left[\left(\Delta L^{*}\right)^{2}+\left(\Delta a^{*}\right)^{2}+\left(\Delta b^{*}\right) 2\right]^{0.5}$

where $\Delta L^{*}, \Delta a^{*}$ and $\Delta b^{*}$ are the derivatives of corresponding parameters.

Statistical analysis

To determine the significance of differences between measurements performed at certain time intervals, in the Experiment I, post hoc multiple comparison tests were performed (Duncan's test was selected). In the Experiment II, the multivariate analysis of variance ANOVA was used for the comparison of more groups separated by a number of categories of variables. It allowed the detection of interaction effects between exposure time and light intensity. All statistical analyses were conducted at $p<0.05$ using Statistica 10.0 (StatSoft Inc., Tulsa, OK, US). The total number of replications used for the statistical analysis is 240 for each treatment $(24$ muscles $\times 2$ steaks from each muscle $\times 5$ measurements at each time interval).

\section{Results and discussion}

\section{Experiment I}

No significant changes in the colour lightness $L^{*}$ during 60 min of Experiment I were observed (Table 1). However, immediately after meat was cut, values of colour parameters $a^{*}$ and $b^{*}$ increased rapidly. This rapid increase proceeded up to 16-18 min after cutting, and after that time, the dynamics of the changes was significantly reduced. The $a^{*}$ value increased from about 16 to about 18 units and the $b^{*}$ value from about 6 to about 12 units. Influenced by increase in $a^{*}$ and $b^{*}$ values, also Chroma $C^{*}$ and $\Delta \mathrm{E}^{*}$ (see Eqs. 1 and 2 ) changed during the first $16 \mathrm{~min}$ of experiment. From 18 up to $60 \mathrm{~min}$ after muscle cutting, all measured values stayed nearly constant. Our findings are in agreement with the results of Resconi et al. [17] and Wulf and Wise [18], who observed that blooming influences rather the redness, yellowness and Chroma than the lightness. Furthermore, similar tendency for the colour parameters, i.e. no changes in $L^{*}$ value and increase in $a^{*}$ and $b^{*}$ 
Table 1 Changes in colour parameters of beef semitendinosus muscle during blooming (mean $\pm \mathrm{SD})$ $(n=48)$
Means in a column with the same superscript letter are not different $(p<0.05)$

\begin{tabular}{|c|c|c|c|c|c|}
\hline \multirow[t]{2}{*}{ Time (min) } & \multicolumn{5}{|l|}{ Parameter } \\
\hline & $L^{*}$ & $a^{*}$ & $b^{*}$ & $C^{*}$ & $\Delta \mathrm{E}^{*}$ \\
\hline 0 & $48.18 \pm 1.03^{\mathrm{a}}$ & $15.80 \pm 1.19^{\mathrm{a}}$ & $5.75 \pm 0.90^{\mathrm{a}}$ & $16.82 \pm 1.06^{\mathrm{a}}$ & - \\
\hline 0.5 & $48.21 \pm 1.14^{\mathrm{a}}$ & $16.08 \pm 0.94^{\mathrm{a}}$ & $7.04 \pm 0.77^{\mathrm{b}}$ & $17.55 \pm 0.66^{\mathrm{a}}$ & $1.46 \pm 0.81^{\mathrm{a}}$ \\
\hline 1 & $48.37 \pm 0.92^{\mathrm{a}}$ & $16.37 \pm 1.22^{\mathrm{ab}}$ & $7.63 \pm 0.83^{b}$ & $18.06 \pm 0.62^{b}$ & $2.28 \pm 1.27^{\mathrm{b}}$ \\
\hline 2 & $48.76 \pm 1.74^{\mathrm{a}}$ & $17.07 \pm 1.17^{\mathrm{bc}}$ & $8.79 \pm 0.89^{c}$ & $19.20 \pm 0.95^{\mathrm{c}}$ & $3.43 \pm 0.62^{\mathrm{c}}$ \\
\hline 3 & $48.82 \pm 0.96^{\mathrm{a}}$ & $17.31 \pm 1.03^{b c}$ & $9.34 \pm 0.75^{\mathrm{c}}$ & $19.67 \pm 1.02^{\mathrm{c}}$ & $4.04 \pm 0.70^{\mathrm{d}}$ \\
\hline 5 & $48.91 \pm 0.94^{\mathrm{a}}$ & $17.57 \pm 1.21^{\mathrm{cd}}$ & $10.05 \pm 0.81^{\mathrm{d}}$ & $20.24 \pm 0.81^{\mathrm{cd}}$ & $4.78 \pm 0.72^{\mathrm{e}}$ \\
\hline 7 & $48.96 \pm 1.47^{\mathrm{a}}$ & $17.66 \pm 0.95^{\mathrm{cd}}$ & $10.61 \pm 0.68^{\mathrm{de}}$ & $20.60 \pm 0.93^{\mathrm{d}}$ & $5.33 \pm 1.23^{\mathrm{ef}}$ \\
\hline 9 & $48.81 \pm 1.25^{\mathrm{a}}$ & $17.83 \pm 1.07^{\mathrm{cd}}$ & $11.02 \pm 0.63^{\mathrm{e}}$ & $20.96 \pm 0.87^{\mathrm{d}}$ & $5.84 \pm 0.88^{\mathrm{f}}$ \\
\hline 14 & $49.33 \pm 1.04^{\mathrm{a}}$ & $18.23 \pm 0.82^{\mathrm{cd}}$ & $11.85 \pm 0.74^{f}$ & $21.74 \pm 0.72^{\mathrm{e}}$ & $6.71 \pm 0.90^{\mathrm{g}}$ \\
\hline 16 & $49.44 \pm 1.29^{\mathrm{a}}$ & $18.37 \pm 0.74^{\mathrm{d}}$ & $12.04 \pm 0.85^{\mathrm{f}}$ & $21.96 \pm 0.85^{\mathrm{e}}$ & $6.96 \pm 0.84^{\mathrm{g}}$ \\
\hline 18 & $49.12 \pm 1.38^{\mathrm{a}}$ & $18.23 \pm 0.86^{\mathrm{cd}}$ & $12.02 \pm 0.91^{\mathrm{f}}$ & $21.83 \pm 0.79^{\mathrm{e}}$ & $6.85 \pm 0.89^{\mathrm{g}}$ \\
\hline 20 & $49.14 \pm 1.89^{\mathrm{a}}$ & $18.18 \pm 0.93^{\mathrm{cd}}$ & $12.12 \pm 0.88^{f}$ & $21.85 \pm 0.70^{\mathrm{e}}$ & $6.91 \pm 0.75^{\mathrm{g}}$ \\
\hline 22 & $48.65 \pm 1.54^{\mathrm{a}}$ & $17.92 \pm 1.01^{\mathrm{bcd}}$ & $11.92 \pm 0.97^{\mathrm{f}}$ & $21.52 \pm 0.92^{\mathrm{e}}$ & $6.61 \pm 1.04^{\mathrm{g}}$ \\
\hline 26 & $49.50 \pm 1.25^{\mathrm{a}}$ & $18.73 \pm 0.79^{\mathrm{cd}}$ & $12.45 \pm 0.62^{\mathrm{fh}}$ & $22.60 \pm 0.73^{\mathrm{f}}$ & $7.66 \pm 0.96^{\mathrm{hi}}$ \\
\hline 30 & $49.22 \pm 1.51^{\mathrm{a}}$ & $18.43 \pm 0.71^{\mathrm{d}}$ & $12.53 \pm 0.58^{\mathrm{fg}}$ & $22.29 \pm 0.56^{\mathrm{e}}$ & $7.37 \pm 0.73^{\mathrm{h}}$ \\
\hline 40 & $49.42 \pm 1.60^{\mathrm{a}}$ & $19.02 \pm 0.68^{\mathrm{e}}$ & $12.93 \pm 0.51^{\mathrm{g}}$ & $23.00 \pm 0.63^{\mathrm{f}}$ & $8.01 \pm 0.63^{\mathrm{i}}$ \\
\hline 50 & $49.38 \pm 1.73^{\mathrm{a}}$ & $19.15 \pm 0.65^{\mathrm{e}}$ & $13.10 \pm 0.47^{\mathrm{g}}$ & $23.20 \pm 0.89^{\mathrm{f}}$ & $8.21 \pm 0.79^{\mathrm{i}}$ \\
\hline 60 & $48.83 \pm 1.47^{\mathrm{a}}$ & $18.74 \pm 0.73^{\mathrm{e}}$ & $12.85 \pm 0.64^{\mathrm{gh}}$ & $22.72 \pm 0.52^{\mathrm{f}}$ & $7.75 \pm 1.13^{\mathrm{hi}}$ \\
\hline
\end{tabular}

values were also observed by Abril et al. [19] when examined colour blooming of bovine muscle longissimus thoracis et lumborum. However, in their study, the blooming of colour proceeded much faster, in only 10 min after cutting. In the study on the surface of pork longissimus muscle, performed by Lindahl et al. [20], a lack of significant changes in $L^{*}$ value up to $90 \mathrm{~min}$ of blooming and a gradual increase in $a^{*}$ and $b^{*}$ values for 30 min was observed. Thus, it can be stated that blooming time of meat colour depends on the species of meat and on its anatomical origin. Muscles, which were more active in the life time, contain more myoglobin and differ in the type of metabolism (muscles with a predominance of aerobic metabolism have more mitochondria). This has an effect on oxygen consumption by the mitochondria, as well as $\mathrm{MMb}$ reducing activity and affects also values of the chromatic parameters during meat blooming. Relationship between oxygen consumption and $\mathrm{MMb}$ reducing activity was already observed by McKenna et al. [21] when studied 19 bovine muscles. They assumed that depending on the type of muscle metabolism.

\section{Experiment II}

Results of the multivariate ANOVA revealed a two-way interaction exposure time $\mathrm{x}$ light intensity. This interaction was statistically significant for all measured parameters. The largest variations of colour lightness were observed for meat exposed to light intensity of 1,500 lx (Fig. 2). Up to $6 \mathrm{~h}$ of exposure, the value of $L^{*}$ parameter was nearly

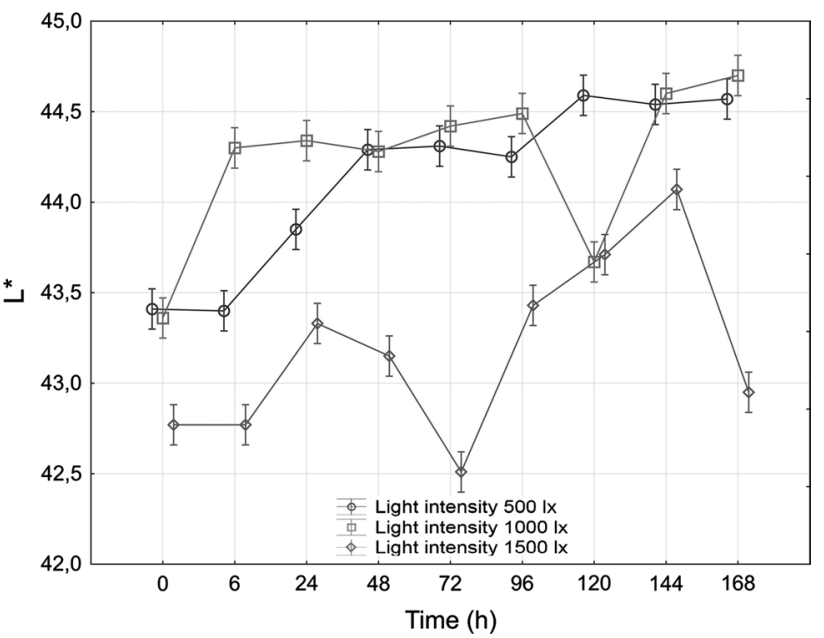

Fig. 2 The impact of exposure time and light intensity on $L^{*}$ value

constant; between 6 and $24 \mathrm{~h}$, it increased significantly; after that, it decreased gradually; in the $72 \mathrm{~h}$ of exposure, it started to increase again; and finally, from the $144 \mathrm{~h}$, it decreased and reached nearly its initial level. Similar to the results of McKenna et al. [21] where beef was exposed to light intensity of $1,614 \mathrm{~lx}$ for $120 \mathrm{~h}$, we have observed only small differences for the $L^{*}$ value when measured at the beginning and the end of experiment; however, its variations during the $168 \mathrm{~h}$ of light exposure were significantly higher. For the steaks exposed to light intensity of 500 and 1,000 lx, the measured lightness showed similar 


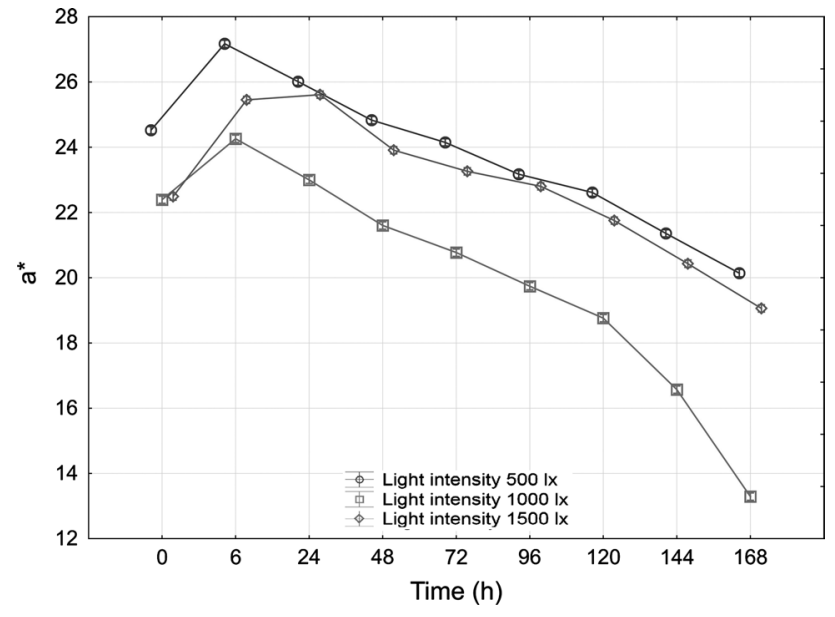

Fig. 3 The impact of exposure time and light intensity on $a^{*}$ value

trends in the course of time, and its values were generally higher, compared with the steaks exposed to light intensity of $1,500 \mathrm{~lx}$. The initial values were equal to 43.4 , and then an increase up to 44.3 was observed. However, for the steaks exposed to light intensity of 1,000 lx, this increase in lightness occurred between 0 and $6 \mathrm{~h}$ of exposure, and for the steaks exposed to light intensity of $500 \mathrm{~lx}$, it between 6 and $48 \mathrm{~h}$. Up to $168 \mathrm{~h}$ of exposure, when the experiment was stopped, the lightness increased further, but this process was much slower, and the final measured values were nearly the same and of about 44.6. The major differences in lightness of meat exposed to light intensity of 500 or $1,000 \mathrm{~lx}$ was an abrupt decrease in its value, measured at $120 \mathrm{~h}$ for the steaks exposed to light intensity of 1,000 lx. Our results agree with observations of Kropf et al. [11] investigating effects of lightening source and intensity on beef quality evaluations. They stated that cool white light caused the darkest lean colour, as well as lean appeared progressively brighter coloured with increasing light intensity.

Concerning the redness, its values measured for the meat exposed to different light intensities showed the same tendency. For the meat exposed to the light of intensities 1,000 and 1,500 lx, $a^{*}$ increased between 0 and $6 \mathrm{~h}$ of exposure, and for the meat exposed to light intensity of $500 \mathrm{~lx}$, between 0 and $24 \mathrm{~h}$, and after that time up to $168 \mathrm{~h}$, its values decreased gradually (Fig. 3). The initial values of $a^{*}$ parameter of steaks exposed to the light intensity of 1,000 and 1,500 $\mathrm{lx}$ were about 22.2, which is significantly lower compared with 24.2 measured for steaks exposed to light intensity of $500 \mathrm{~lx}$. At the $24 \mathrm{~h}$ of exposure, the redness of meat exposed to light intensity of $500 \mathrm{~lx}$ reached the same value as the redness of meat exposed to light intensity of 1,500 $\mathrm{lx}$, and from this time, their changes were nearly identical. From $6 \mathrm{~h}$ of exposure, the redness of

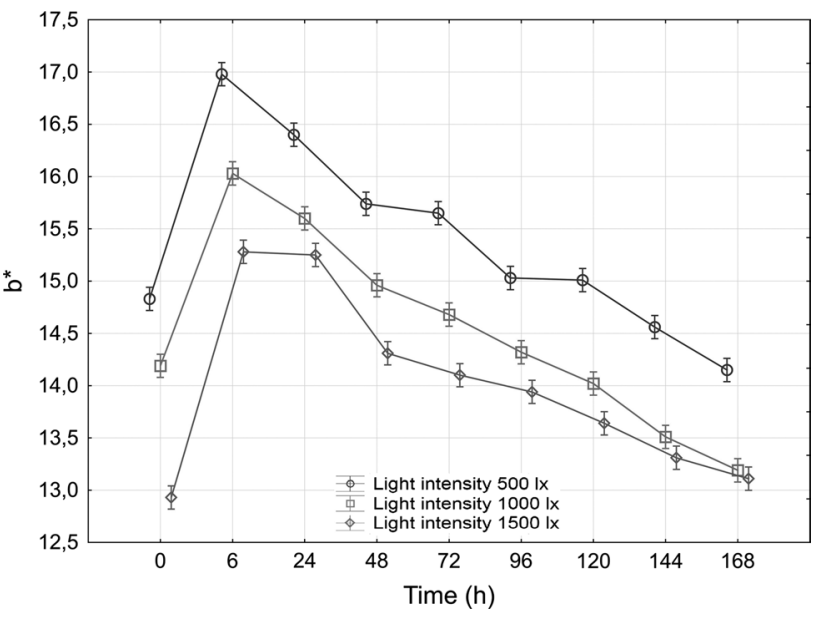

Fig. 4 The impact of exposure time and light intensity on $b^{*}$ value

steaks exposed to light intensity of 1,000 lx decreased with nearly the same ratio as the two others and was constantly lower compared with them. The final value of about 13 of $a^{*}$ parameter for meat exposed to light intensity of $1,000 \mathrm{~lx}$ was lower by about 6 units as compared to the value of $a^{*}$ parameter for meat exposed to light intensity of 500 and 1,500 lx. However, one would be expected that a greater light intensity would have a more discoloration. Conditions of the experiment were chosen to eliminate the differentiating factors such as $\mathrm{pH}$ and temperature of meat, humidity and air circulation in the chamber. Therefore, it can be assumed that only one factor was variable - the light intensity. This greater discoloration is probably a purely physical phenomenon, which at this stage of our research, we are not able to explain. In previous study, McKenna et al. [21] noted an increase in $a^{*}$ parameter value up to $24 \mathrm{~h}$ of exposure. Such a long period of time in increase in $a^{*}$ value was unexpected because before the light exposure, meat samples were exposed to the oxygen in order for colour blooming. This long time of increases in $a^{*}$ parameter can be explained by still relatively high oxygen consumption rate of mitochondria in muscles up to 96-h post-mortem, which reduces the formation of $\mathrm{OMb}$ [22].

As shown in Figs. 4 and 5, the highest values of yellowness $\left(b^{*}\right)$ and Chroma $\left(C^{*}\right)$ were observed in meat exposed to light intensity of $500 \mathrm{~lx}$ and the lowest values: $b^{*}$ in meat exposed to light intensity of $1,500 \mathrm{~lx}$ and $C^{*}$ for $1,000 \mathrm{~lx}$. Trends of $b^{*}$ and $C^{*}$ parameters were similar, and they were the same for all three measured light intensities. Between 0 and $6 \mathrm{~h}$ of exposure, $b^{*}$ and $C^{*}$ values increased by about $2-3$ units, and from the $6 \mathrm{~h}$ gradual decrease up to the $168 \mathrm{~h}$ was observed. The final value of $b^{*}$ parameter of meat exposed to light intensity of $500 \mathrm{~lx}$ was 14.1 and was higher by more than 1 unit when compared to the $b^{*}$ value of meat exposed to two other light intensities. In 


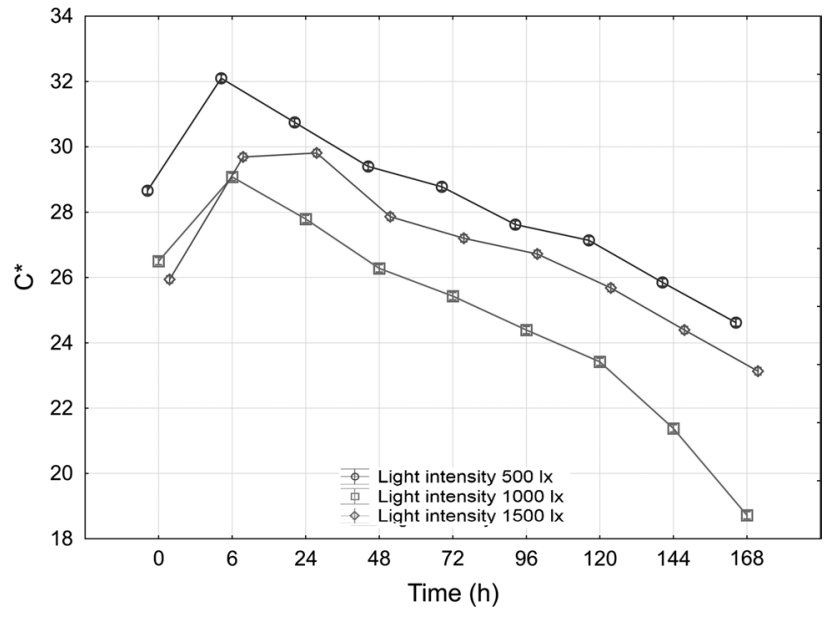

Fig. 5 The impact of exposure time and light intensity on $C^{*}$ value

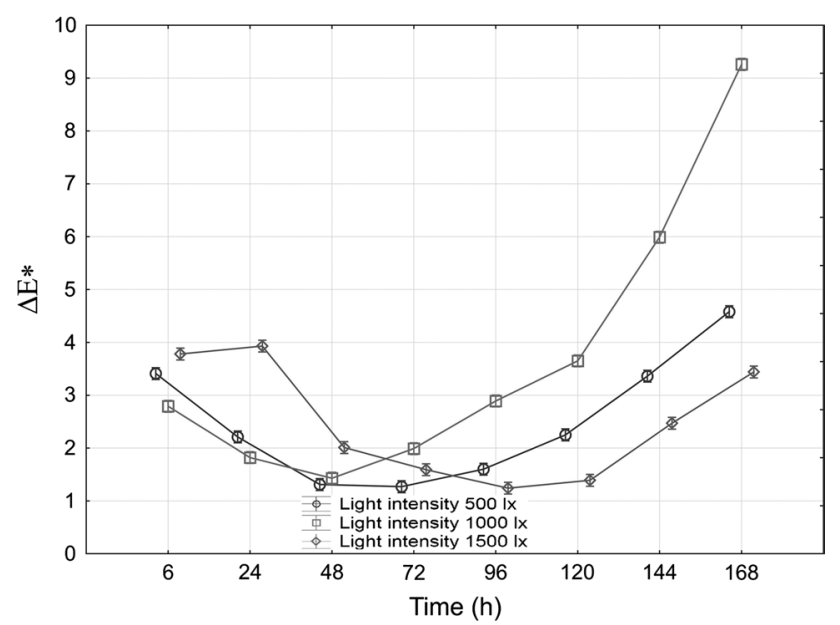

Fig. 6 The impact of exposure time and light intensity on $\Delta E^{*}$ value

an experiment of Lee et al. [9] performed with light intensity of $1,000 \mathrm{~lx}$, an increase in $b^{*}$ and $C^{*}$ parameters was observed for a longer time, up to the $24 \mathrm{~h}$ of exposure. Zhu and Brewer [10] observed higher concentration of $\mathrm{MMb}$ on the surface of meat exposed to the light than on the surface of meat stored in the dark. Andersen et al. [23] noted that a fluorescent light increased the degree of OMb oxidation to MMb. Based on these finding, one can conclude that gradual decrease in $a^{*}, b^{*}$ and $C^{*}$ values between 24 and $168 \mathrm{~h}$ observed in our experiment results from accumulation of larger amount of $\mathrm{MMb}$ on the meat surface. Furthermore, $\mathrm{MMb}$ concentration in the total amount of haem pigments increased with increasing light intensity. Increase in the rate of $\mathrm{MMb}$ formation resulting from fluorescent light exposure is in agreement with results published by King et al. [24]. They studied the interaction of the initial and the final levels of oxygen consumption and reducing activity as a consequence of colour individual variability for longissimus muscles exposed for 6 days to light intensity of 2,000 1x. During the 6 days of exposure, values of colour parameters, oxygen consumption and reducing activity were reduced. Nevertheless, the steaks with stable colour were characterized by higher reducing activity and lower oxygen consumption at day 0 when compared to the steaks with less stable colour.

Figure 6 shows that the meat exposed to the light, independent on the light intensity, was characterized by relatively high $\Delta \mathrm{E}^{*}$ values at the beginning of the experiment. The changes of $\Delta \mathrm{E}^{*}$ parameter showed initially decreasing tendency and then from $96 \mathrm{~h}$ of exposure started to increase. Meat exposed to light intensity of 1,500 lx was characterized by the largest total changes in its colour in the first half of experiment (up to $96 \mathrm{~h}$ ). In the second half of experiment (from 96 to $168 \mathrm{~h}$ ), the total colour changes of meat were the lowest compared with meat exposed to two other light intensities. Meat exposed to light intensity of 1,000 lx was characterized by the lowest initial, but the highest final $\Delta \mathrm{E}^{*}$ value. The final $\Delta \mathrm{E}^{*}$ was equal 9.2 and higher by, respectively, about 6 and about 5 units when compared to meat exposed to light intensity of 1,500 and 500 lx. Lindström [25] and Fleishman et al. [26] stated a.o. that the standard observer can see small differences in colour when $\Delta \mathrm{E}^{*}>2$, and for $\Delta \mathrm{E}^{*}>5$, the changes are already so significant that two different colours are clearly distinguishable. Thus, it can be concluded, that regardless of the light intensity, between 6 and $24 \mathrm{~h}$, the total changes of colour were clearly recognized. For meat exposed to light intensity of 500 and 1,500 lx, no visible colour changes were observed between 48 and $120 \mathrm{~h}$, and the values of $\Delta \mathrm{E}^{*}$ did not exceed five during the entire time of experiment. For meat exposed to light intensity of 1,000 lx, colour gradually changed from 72 up to $168 \mathrm{~h}$, and between 120 and $144 \mathrm{~h}$, it gives the impression of being two different colours.

\section{Conclusion}

It is shown that, it takes up to $16-18$ min for the colour parameters to stabilize after the steak cutting. The observed significant changes in the colour of fresh beef cross section in the Experiment I were induced by increasing availability of oxygen. The largest changes were observed for $b^{*}$ parameter. The undesired changes in the chromatic parameters of colour, resulted from exposure to the light, are not proportional to the light intensity and mostly take place in the final stage of the exposure. It may be due to the fact that meat exposure to the light initiates a lot of different physical and chemical processes that lead to destruction of haem pigments and changes in the proportion of the various 
myoglobin forms. Based on the obtained results, it can be concluded that the white fluorescent light with colour temperature of $3,000 \mathrm{~K}$ and the intensity of $500 \mathrm{~lx}$ is more favourable to maintain the desired beef colour during exposure, than light intensity of 1,000 and 1,500 lx. However, further studies taking into account the visual evaluation of beef colour would be useful to confirm this fact.

Conflict of interest Marek Cierach and Jacek Niedźwiedź declare that they have no conflict of interest.

Compliance with Ethics Requirements All institutional and national guidelines for the care and use of laboratory animals were followed.

Open Access This article is distributed under the terms of the Creative Commons Attribution License which permits any use, distribution, and reproduction in any medium, provided the original author(s) and the source are credited.

\section{References}

1. Mancini RA, Hunt MC (2005) Current research in meat color. Meat Sci 71:100-121

2. Warriss PD, Brown SN, Paściak P (2006) The colour of the adductor as a predictor of pork quality in the loin. Meat Sci 73:565-569

3. Li Y, Liu S (2012) Reducing lipid peroxidation for improving colour stability of beef and lamb: on-farm considerations. J Sci Food Agric 92:719-726

4. Muramoto T, Higashiyama M, Kondo T (2004) Comparison of beef color stability during display of two muscles between Japanese Shorthorn steers and Japanese Black steers. Asian Aust J Anim 17:1303-1308

5. Faustman C, Cassens RG (1990) The biochemical basis for discoloration in meat: a review. J Muscle Foods 1:217-243

6. Bekhit AED, Geesink GH, Ilian MA, Morton JD, Bickerstaffe R (2003) The effects of natural antioxidants on oxidative processes and metmyoglobin reducing activity in beef patties. Food Chem 81:175-187

7. Cornforth DP (1994) Color: its basis and importance. In: Pearson AM, Dutson TR (eds) Quality attributes and their measurement in meat, poultry and fish products. Aspen Publishers Inc, US, pp 34-39

8. Livingston DJ, Brown WD (1981) The chemistry of myoglobin and its reactions. Food Technol 25:244-252

9. Lee SK, Kim YS, Kim JY, Song YH (2001) Effect of muscle $\mathrm{pH}$ and display conditions on surface color in Hanwoo (Korean Native Cattle) Beef. Asian Aust J Anim 14:365-371
10. Zhu LG, Brewer MS (1998) Discoloration of fresh pork as related to muscle and display conditions. J Food Sci 63:763-767

11. Kropf DH, Dikeman ME, Hunt MC, Cross HR (1984) Lighting type and intensity effects on beef carcass grade factors. J Anim Sci 59:105-108

12. Barbut S (2005) Effect of enhanced fluorescent light on acceptability of meat cuts. J Muscle Foods 16:77-86

13. COUNCIL REGULATION (EC) No 1099/2009 of 24 September 2009 on the protection of animals at the time of killing

14. Niedźwiedź J, Ostoja H, Cierach M (2012) Texture of longissimus thoracis et lumborum muscles from beef cattle crossbreeds subjected to wet aging. Acta Agrophys 19:631-640

15. Billmeyer FW, Saltzman M (1981) Principles of colour technology. Willey, New York

16. Clydesdale FM (1978) Colorimetry-methodology and applications. Crit Rev Food Sci 10:243-301

17. Resconi VC, Escudero A, Beltrán JA, Olleta JL, Sañudo C, del Mar Campo M (2012) Color, lipid oxidation, sensory quality, and aroma compounds of beef steaks displayed under different levels of oxygen in a modified atmosphere package. J Food Sci $71: 10-18$

18. Wulf DM, Wise JW (1999) Measuring muscle color on beef carcasses using the $\mathrm{L} * \mathrm{a} * \mathrm{~b} *$ color space. J Anim Sci 77:2418-2427

19. Abril M, Campo MM, Onenç A, Sañudo C, Albertí P, Negueruela AI (2001) Beef colour evolution as a function of ultimate $\mathrm{pH}$. Meat Sci 58:69-78

20. Lindahl G, Karlsson AH, Lundström K, Andersen HJ (2006) Significance of storage time on degree of blooming and colour stability of pork loin from different crossbreeds. Meat Sci 72:603-612

21. McKenna DR, Mies PD, Baird BE, Pfeiffer KD, Ellebracht JW, Savell JW (2005) Biochemical and physical factors affecting discoloration characteristics of 19 bovine muscles. Meat Sci 70:665-682

22. Ledward DA, Johnston DE, Knight MK (1992) The chemistry of muscle-based foods, in The Royal Society of Chemistry. Thomas Graham House, Science Park

23. Andersen HJ, Bertelsen G, Skibsted LH (1990) Colour and colour stability of hot processed frozen minced beef: results from chemical model experiments tested under storage conditions. Meat Sci 28:87-97

24. King DA, Shackelford SD, Rodriguez AB, Wheeler TL (2011) Effect of time of measurement on the relationship between metmyoglobin reducing activity and oxygen consumption to instrumental measures of beef longissimus color stability. Meat Sci $87: 26-32$

25. Lindström P (2008) Delta E Blues: the Science of color perception. Seybold Report: Analyzing Publishing Technologies 8(3):13

26. Fleishman LJ, McClintock WJ, D'Eath RB, Brainard DH, Endler JA (1998) Colour perception and the use of video playback experiments in animal behaviour. Anim Behav 56:1035-1040 